Available online on 15.7.2019 at http://ujpr.org
Universal Journal of Pharmaceutical Research
This is an open access article distributed under the terms of the Creative Commons Attribution-Non
Open access to Pharmaceutical research
Commercial Share Alike 4.0 License which permits unrestricted non commercial use,
provided the original work is properly cited
Volume 4, Issue 3, 2019

\title{
PREVALENCE AND POTENTIAL RISK FACTORS OF HEPATITIS B VIRUS IN A SAMPLE OF CHILDREN IN TWO SELECTED AREAS IN YEMEN

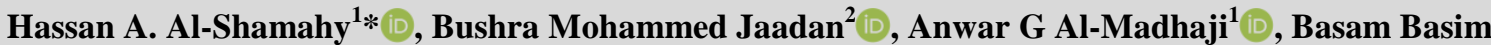

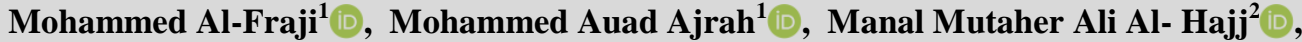 Ahmed Mohamed Al-Hadad ${ }^{3}$ D \\ ${ }^{I}$ Department of Medical Microbiology and Clinical Immunology, Faculty of Medicine and Health Sciences, Sana' a University. ${ }^{2}$ Medicinal Chemistry, Faculty of Pharmacy, Sana'a University, Republic of Yemen. \\ ${ }^{3}$ Department of Medical Microbiology, Faculty of Medicine and Health Sciences, Hadhramout University, Republic of Yemen.
}

\section{ABSTRACT}

Objective: The global epidemic of hepatitis B is a significant public health problem. The endemicity of HBV infection used to be believed high in Yemen. Data for the prevalence of HBsAg among children in rural and urban areas in Yemen is scarce and incompetent. The study was made to determine prevalence of HB surface antigen among children in 2 selected areas in Yemen. Methods: Eight hundred forty and 212 children were randomly chosen from Sana'a city and Shabowah governorate, respectively. Sera were tested for HBs antigen by ELISA technique, and HB genome was tested for positive HB surface antigen specimens to confirm positivity using polymerase chain reaction (PCR)-based test. Each data collected in a pre-designed questionnaire including sex, age, and risk factors of HBV and prior vaccine of HBV.

Results: The prevalence of HB surface antigen among children in Sana'a city was only $1.8 \%$, and in Shabowah governorate was $3.8 \%$. There was a significant association of non-vaccinated children, birth by cesarean, and with a history of parental exposure with contracting HBV infection.

Conclusion: Evidence from these studies in Yemen suggests that there is a steady increase in exposure to HBV over a lifetime. Hospital-acquired HBV infection is common in Yemen, and high vaccination coverage rate should be achieved, particularly in rural areas, in parallel with health education.

Keywords: Children, Epidemiology, Hepatitis B virus, risk factors, Yemen.

Article Info: Received 1 May 2019; Revised 16 June; Accepted 8 July, Available online 15 July 2019

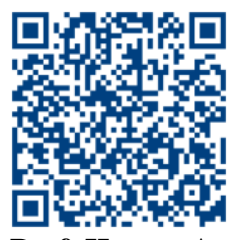

Cite this article-

Al-Shamahy HA, Jaadan BM, Al-Madhaji AG, Al-Fraji BBM, Ajrah MA, Al- Hajj MMA, Al-Hadad AM. Prevalence and potential risk factors of hepatitis B virus in a sample of children in two selected areas in Yemen. Universal Journal of Pharmaceutical Research 2019; 4(3): 17-21.

DOI: https://doi.org/10.22270/ujpr.v4i3.269

Address for Correspondence

Prof. Hassan A. Al-Shamahy, Faculty of Medicine and Heath Sciences, Sana'a University, P.O. Box 775 Sana'a, Yemen. Phone: +967-770299847, E-mail: shmahe@yemen.net.ye.

\section{INTRODUCTION}

Hepatitis B virus (HBV) infection is a significant global health problem, with 2 billion people infected worldwide, and 350 million suffering from chronic HBV infection. The $10^{\text {th }}$ leading cause of death worldwide, HBV infections result in 500000 to 1.2 million deaths per year caused by chronic hepatitis, cirrhosis, and hepatocellular carcinoma; the last accounts for 320000 deaths per year ${ }^{1,2,3}$. In developed countries, the disease is relatively rare and gained primarily in adulthood in which injection drug abuse and unprotected sex are the main methods, where in Asia and the majority of Africa including Yemen, chronic HBV infection is widespread and typically acquired parenterally or in infancy ${ }^{4-8}$. The endemicity of HBV was estimated high in Yemen, anywhere the prevalence of positive $\mathrm{HBsAg}$ among adult's ranges from $8 \%$ to $20 \%$, among infants, was $4.1 \%$, and up to $50 \%$ of the populations commonly have serological evidence of previous HBV infection in old reports ${ }^{9-15}$. On the other hand, recent studies reported a lower rate of HBsAg in which it ranges from $0.7-2 \%$ among general population as well as children ${ }^{16,17,18}$. More efficacious treatments, mass immunization programs, and safe injection techniques are essential for eliminating HBV infection and reducing global HBVrelated morbidity and mortality ${ }^{19}$. Reliable and efficient vaccines for HBV infection have been obtainable since 1982. The applications of mass immunization programs, which have been suggested by the WHO since 1991, have considerably decreased the incidence of HBV infection among infants, children, and 
adolescents in many countries ${ }^{1,2}$. However, not all countries have adopted these recommendations, and there remains a large number of persons that were infected with HBV which including Yemen in which the coverage rate of $\mathrm{HBV}$ vaccine in urban was only $69.9 \%,{ }^{3,17}$. The main aim of this study is to determine the prevalence of HB surface antigen among a sample of children in 2 selected areas in Yemen and analysis potential risk factors of $\mathrm{HBV}$ transmission among the chosen children.

\section{SUBJECTS AND METHODS \\ Study area}

This cross-sectional sero epidemiological study was conducted in healthy children less than 11 years of age in Sana'a city and in healthy children less than 16 years of age in Shabwah governorate Yemen. Yemen is situated on Southwest Asia in the Arabian Peninsula. It is bounded by the Red Sea to the west, Sultanate of Oman to the east, Saudi Arabia to the north and the Arabian Sea to the south. In 2008 the population was estimated at 21,843,554, living in 3,058,299 households. The structure of the population is characteristic of a developing country, by the rural population counting $71 \%$ of the total. The majority of the inhabitants are young, with $45 \%$ below age 15 years, while the over 64 years age group represents only $3.4 \%$. The literacy rate is $47 \%$ among those 15 years and older (males 63\%, females $31 \%$ ), the average household size 7.1 persons, the fertility rate 6.2 , the annual growth rate of population $2.9 \%$ and the poverty rate about $47 \%$.

Life expectancy at birth female/male is 67/63 years, and the probability of dying under five years in 2019 was 320/1000 live births. These and other factors as Saudi /Emirates aggression contribute to Yemen's low ranking in the Development Index cited in the World Human Development Report-178 among the 189 countries that were rated in the year $2018^{20}$. Yemen introduced universal immunization against $\mathrm{HBV}$ for infants and high-risk groups in early 2000, but feedback on the coverage rate of vaccination and its efficacy in the community have been ignored for a long period. Also, there has been inadequate information on the prevalence and risk determinants of viral hepatitis as well as on vaccination coverage rate among children in Yemen. UNICEF provided the vaccines from different reliable sources.

\section{Study populations and Sample size}

This cross sectional study was carried out during 3 months, starting in January 2016 and ending in March 2016, after the approval of the Department of Medical Microbiology, in the Faculty of Medicine and Health Sciences, Sana'a University to the study proposal. A consent form was filled by the parents for each participant. The sample sizes for or study was calculated as follow: First we considered the rate of HBV in Sana'a city, difference (worst acceptable result higher or lower the true rate) and confidence interval as $2 \%, 0.5 \%$ and $95 \%$ respectively. According to calculations, a sample size of at least 752 subjects was required from the population of children under 11 years in Sana'a city $(639358 \text { children })^{\mathbf{2 0}}$ which the sample will be selected; this was selected by systematic random method. All health centers and primary schools in Sana'a were listed ( 27 centers, 33 schools), then by simple random selection 4 of these centers and 4 of these schools were selected; finally, every $5^{\text {th }}$ child admitted to these health centers for normal check and vaccination was selected (about $17 \%$ of male children and $13 \%$ of female children who refused to donate blood were excluded), and, every 5th child in the selected classes was selected (about $7 \%$ of male children and $6 \%$ of female children who refused to donate blood were excluded).

Second, it was considered that the rate of $\mathrm{HBV}$ in Shabwah governorate, the difference (worst acceptable result higher or lower the true rate) and confidence interval as $3 \%, 0.5 \%$ and $95 \%$ respectively. According to calculations of current study, a sample size of at least 178 subjects was required from the population of children under 16 years in Shabwah governorate (255600 children $)^{\mathbf{2 0}}$ which the sample will be selected; this was selected by systematic random method. All health centers and primary schools in Atag, Bayhan and Mayfa'a in Shabwah governorate were selected (3 centers, 4 schools), then every 5 th child admitted to these health centers for normal check and vaccination was selected (about $36 \%$ of male children and $39 \%$ of female children who refused to donate blood were excluded), and, every $5^{\text {th }}$ child in the selected classes was selected (about $14 \%$ of male children and $9 \%$ of female children who refused to donate blood were excluded).

\section{Data collection}

A full history was taken from each studied individual or from parents; and the findings were recorded in a predesigned questionnaire. The data collected included name, age at the time of the study, sex, residence, status and risk factors of $\mathrm{HBV}$ contracting; and laboratory results.

\section{Laboratory tests}

Capillary blood or vein puncture of whole blood was collected; then sera were separated and tested for HB surface antigen by an Enzyme-linked Immunosorbant assay (ELISA) using a commercially available kit provided by Biokit, Spain.

Specimens which proved repeatedly reactive by EIA in two separate tests were considered positive for hepatitis $B$ surface antigen. In addition HB genome was tested for positive $\mathrm{HB}$ surface antigen specimens to confirm positivity using a commercial polymerase chain reaction (PCR) -based test (Taqman amplicor, Roche, USA) and all were positive.

\section{Statistical analysis}

Personal and clinical data were obtained from each subject and recorded into a pre-designed questionnaire, then the data were statistically analyzed by a software version for statistical significance (Epi Info version 6, CDC, Atlanta, USA).

From two-by-two tables, the odds ratios were calculated and $P$-value was determined using the uncorrected chi square test. Fisher's exact test was used for the small expected cell sizes with a two-tailed probability value. 
Table 1: Prevalence of HB surface antigen in different age groups and risk factor analysis of HBV in a sample of children under 10 years old, in Sana'a city, Yemen.

\begin{tabular}{|c|c|c|c|c|c|}
\hline \multirow[t]{2}{*}{ Age groups } & \multicolumn{2}{|c|}{ HB S Ag positive } & \multirow[t]{2}{*}{ OR } & \multirow[t]{2}{*}{$C I$} & \multirow{2}{*}{$\begin{array}{c}P \\
\text { value }\end{array}$} \\
\hline & No. & $\%$ & & & \\
\hline $1-2$ years $(n=119)$ & 1 & 0.85 & & & \\
\hline \multicolumn{6}{|l|}{ Reference } \\
\hline $3-5$ years $(n=274)$ & 5 & 1.8 & 2.1 & $0.25-18.9$ & 0.46 \\
\hline $6-8$ years $(n=273)$ & 5 & 1.8 & 2.2 & $0.25-19$ & 0.46 \\
\hline $9-10$ years $(n=174)$ & 4 & 2.3 & 2.7 & $0.3-25$ & 0.3 \\
\hline Total $(n=840)$ & 15 & 1.8 & & & \\
\hline \multicolumn{6}{|c|}{ Factors } \\
\hline \multicolumn{6}{|l|}{ Vaccinated to HBV } \\
\hline Yes $(n=504)$ & 4 & 0.79 & & & \\
\hline \multicolumn{6}{|l|}{ Reference } \\
\hline No $(n=336)$ & 11 & 3.3 & 4.2 & $1.23-15.9$ & 0.007 \\
\hline $\begin{array}{l}\text { Birth in hospital } \\
(\mathrm{n}=334)\end{array}$ & 7 & 2 & 1.27 & $0.41-3.9$ & 0.64 \\
\hline $\begin{array}{l}\text { No }(n=506) \\
\text { Reference }\end{array}$ & 8 & 1.6 & & & \\
\hline \multicolumn{6}{|l|}{ Birth by cesarean } \\
\hline Yes $(n=39)$ & 2 & 5.1 & 3.3 & $0-16$ & 0.1 \\
\hline No $(n=801)$ & 13 & 1.6 & & & \\
\hline \multicolumn{6}{|l|}{ Reference } \\
\hline \multicolumn{6}{|l|}{ Parental exposure } \\
\hline Yes $(n=72)$ & 4 & 5.6 & 4.05 & $1.1-14.3$ & 0.01 \\
\hline N0 $(n=768)$ & 11 & 1.4 & & & \\
\hline Reference & & & & & \\
\hline
\end{tabular}

Table 2: Prevalence of $\mathrm{HB}$ surface antigen in different age groups and risk factor analysis of $\mathrm{HBV}$ in a sample of children under 15 years old, in Shabowah governorate, Yemen.

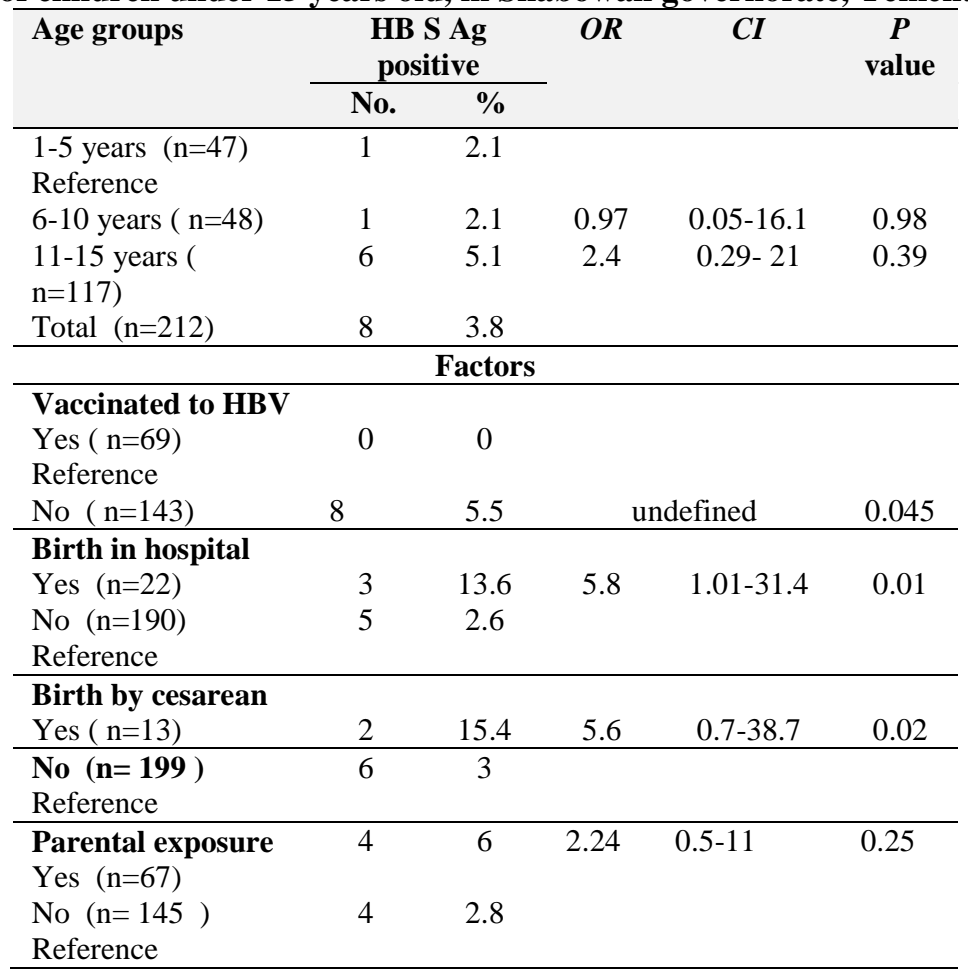

\section{RESULTS}

Table 1 and Table 2 outline prevalence and the odds ratio (OR) estimates by their $95 \%$ confidence intervals $(95 \% \mathrm{CI})$, and by Fisher's exact test for cell value less than 5 , for positive serological tests of hepatitis B virus and expected risk factors of contracting Hepatitis B virus, and with statistically significant $P$-value using uncorrected chi-square test. The crude sero prevalence among children in Sana'a city was $1.8 \%$ and it was
$3.8 \%$ for children from Shabowah governorate. When the age of children was considered, the highest rate of HBV among children in Sana'a city was in age group 9-10 years $(2.3 \%)$, with associated OR equal to 2.7 , $\mathrm{CI}=0.3-25$, but this result was not statistic significance $(p=0.3)$. The lowest rate of HBV among children in Sana'a city was in age group $1-2$ years $(0.85 \%)$ as shown in Table 1. The highest rate of HBV among children in Shabwah governorate was in age group 11- 
15 years $(5.1 \%)$, with associated OR equal to 2.4, $\mathrm{CI}=0.29-21$, but this result was not statistic significance $(p=0.39)$. The rates of HBV in Shabwah in age groups 1-5 years and 6-10 years were similar (2.1\%). In conclusion there was non-significant effect of older age on contracting hepatitis B virus in both selected area children (Table 1, and Table 2). In the case of risk factors of hepatitis B virus infection for children in Sana'a city, there was a significant association of non vaccination to $\mathrm{HBV}$ vaccine $(\mathrm{OR}=4.2, \mathrm{CI}=1.23-15.9$, $p=0.007)$, and with history of parental exposure $(\mathrm{OR}=4.05, \mathrm{CI}=1.1-14.3, p=0.01)$. Also there was not significant association of birth by cesarean in which $\mathrm{OR}=3.3, \mathrm{CI}=0.0-16, p=0.1)$ and birth in hospital $(\mathrm{OR}=1.27, \mathrm{CI}=0.41-3.9, p=0.64)$ (Table 1$)$. In the case of risk factors of hepatitis B virus infection for children in Shabwah governorate, it was found that there was a highly significant association of contracting $\mathrm{HBV}$ infection with non vaccination to $\mathrm{HBV}$ vaccine with significant rate equal to $5.5 \%$ (OR and $\mathrm{CI}=$ undefined, $p=0.045)$, birth in hospital $(\mathrm{OR}=5.8, \mathrm{CI}=1.01$ - 31.4, $p=0.01)$ and birth by cesarean $(\mathrm{OR}=5.6, \mathrm{CI}=0.7-38.7$, $p=0.02)$, but not significant with history of parental exposure $(\mathrm{OR}=2.24, \mathrm{CI}=0.5-11, p=0.25)$ (Table 2).

\section{DISCUSSION}

The prevalence rate of $\mathrm{HB}$ surface antigen in current study was variants among selected healthy children in the two selected areas these differences in the prevalence rates might be the geographical differences and the national immunization programme vaccination coverage in the capital city of Sana'a (high) and urban area of Shabowah (low) and or related to the differences in the classification of age groups. The prevalence rate in current study in Sana'a city was $1.8 \%$, is lower than that reported among infants in Sana'a city previously where the rate was $4.1 \%$ but the rate in Shabwah $(3.8 \%)$ is roughly similar to that reported previously in Sana'a city among infants ${ }^{10}$. Although it is difficult to compare the prevalence rates reported in current study (among children), with that reported by Al-Shamahy et al. ${ }^{10,11}$ (among children and mothers and among blood donors etc), it seems that the rate of HBsAg has decreased dramatically. Introducing hepatitis $\mathrm{B}$ vaccine within the national immunization program improvement of the people's knowledge about hepatitis risk factors through educational program, and the availability of measures to diagnose hepatitis in health centers and blood banks might explain this decrease $\mathrm{s}^{16,18,21}$.

The rates of HBV in current study was higher than that reported in Northern, Western, and central Europe, North America, and Australia, children and general population where the rates of HBV surface antigen was ranged from $0.2-0.5 \%,{ }^{22}$. In other hand the crude rate of HBV surface antigen in current study was similar to that reported in Eastern Europe, the Mediterranean, Russia and the Russian Federation, Southwest Asia, Central and South America among children general population where the rates of HBV surface antigen was ranged from $2-7 \%$, but lower than that reported in Parts of China, Southeast Asia, and tropical Africa among general population where the rates of $\mathrm{HBV}$ surface antigen was ranged from $8-20 \%{ }^{22}$. These differences in the prevalence rates might be explained by the geographical differences in the availability of services and vaccination programmers. Many other studies in nearby countries have shown a lower prevalence of hepatitis B among children, as Saudi Arabia $(0.05 \%)^{24}$, This may be because the good availability of services and vaccination programmers in Saudi Arabia and there is insufficient protection for patient children admitted to hospitals in Yemen, since sterilization, disinfection and general standards of training and proficiency are generally lacking in most hospitals in Yemen.

HBV infection affects all age's everywhere ${ }^{22-26}$. There was slightly trend toward increased levels of $\mathrm{HB}$ surface antigen with the older children where prevalence rate is ranged from $0.84 \%$ in $1-2$ years group to $2.3 \%$ in 6-8 years group in Sana'a city and this trend toward increased levels of HB surface antigen with the older children is more clear in Shabowah governorate where the rate is ranged from $2.1 \%$ in $1-5$ years old to $5.1 \%$ in $11-15$ years group (Table 1 , Table 2 ). The increasing of prevalence rate with increasing age in current study could indicate an accumulation risk of infection over time. In addition, the results indicated that horizontal spread of HBV may be of greater importance than vertical transmission. The study illustrates that children in Yemen mainly in rural areas as Shabowah governorate are at a high risk of becoming infected in their early years. The first risk for infection occurs in the first few days spent in hospitals during normal delivery $(\mathrm{OR}=5.84, p=0.01)$ or by cesarean section $(\mathrm{OR}=5.6, p=0.02)$, and this confirms that use of unsterilized or inadequately sterilized contaminated instruments are a possible route of infection. It is possible that there was insufficient protection for children admitted to hospitals in Yemen. Sterilization, disinfection and general standards of training and proficiency are generally deficient in most hospitals in Yemen particularly in rural areas.

The rate of HBV infection was higher in Shabowah area $(3.8 \%)$ than in Sana'a city this regional variation might be due to non-uniformities in immunization and engagement in risky behaviors across different sites. Also current study shows the important of HBV vaccine in prevent infections (Table 1 and Table 2) in which higher risk of contracting HBV infection among non-vaccinated children and more $\mathrm{HBs} \mathrm{Ag}$-positive cases were from unvaccinated children and rural area suggesting of poorer vaccination coverage of the rural population. Evidence from these studies in Yemen suggests that there is a steady increase in exposure to HBV over a lifetime. Hospital-acquired HBV infection is very common in Yemen, and prevention is eventually possible by applying standard policies of sterilization, disinfection and personal training to implement this policy and guarantee refinements in the screening of blood donors. In Yemen, vaccination should be considered for all children and programs to immunize all newborn Babies with a goal of $80 \%$ coverage or more should be performed in the next 2 to 4 years particularly in rural areas, in the same with health education. 


\section{CONCLUSION}

There was a significant association of non-vaccinated children, birth by cesarean, and with history of parental exposure with contracting HBV infection. Evidence from these studies in Yemen suggests that there is a steady increase in exposure to HBV over a lifetime. Hospital-acquired HBV infection is very common in Yemen, and high vaccination coverage rate should be achieved particularly in rural areas, in parallel with health education.

\section{ACKNOWLEDGEMENTS}

The authors would like to acknowledge, Sana'a University and the National Center of Public Health Laboratories (NCPHL) Sana'a, Yemen for support and provided working space and materials.

\section{AUTHOR'S CONTRIBUTION}

This research work is part of 2 M.Sc. theses. The candidates are the fourth and fifth authors (BBMA) who conducted the field works and the experiments and wrote up the thesis. The corresponding author (HAA) supervised the experimental work, revised and edited the thesis draft and the manuscript. (BMJ) and (AGA) were co-advisor of the works, and helped in supervised the experimental work, revised and edited the thesis draft and the manuscript.

\section{CONFLICT OF INTEREST}

No conflict of interest associated with this work.

\section{REFERENCES}

1. Williams R. Global challenges in liver disease. Hepatology (Baltimore, Md.) 2006, 44 (3): 521-526. https://doi.org/10.1002/hep.21347

2. Schilsky ML. Hepatitis B "360". Transplantation Proceedings 2013, 45 (3): 982-985.

3. Custer B, Sullivan SD, Hazlet TK, Iloeje U, Veenstra DL, Kowdley KV. Global epidemiology of hepatitis B virus. J Clin Gast 2004; 38 (10 Suppl 3): S158-68. https://doi.org/10.1016/j.vaccine.2011.12.116

4. Buddeberg F, Schimmer BB, Spahn DR. Transfusiontransmissible infections and transfusion-related immunomodulation. Best Practice and Research. Clin Anaesthesiol 2008; 22 (3): 503-17.

https://doi.org/10.1016/j.bpa.2008.05.003

5. Hughes RA. "Drug injectors and the cleaning of needles and syringes". Europ Add Res 2000; 6 (1): 20-30.

6. Hepatitis B -the facts: IDEAS -Victorian Government Health Information, Australia. State of Victoria. 2009-07-28. Retrieved 2009-09-19.

7. Shapiro CN. Epidemiology of hepatitis B. Pediatr Infect Dis J. 1993; 12 (5): 433-437. https://doi.org/10.7150/ijms.2.50

8. Komas NP, Vickos U, Hübschen JM, Béré A, Manirakiza A, Muller CP, Le Faou A. Cross-sectional study of hepatitis B virus infection in rural communities, Central African Republic. BMC Infect Dis 2013; 13: 286. https://doi.org/10.1186/1471-2334-13-286

9. Al- Nassiri K A, Raja'a Y A. Sana'a Pattern and risk factors of Hepatitis B among Yemeni Peoples in Sana'a. Middle East J. WHO 2001; 7 (1/2).
10. AL-Shamahy H. Prevalence of Hepatitis B surface antigen and Risk factors of HBV infection in samples of healthy mothers and their infants in Sana'a, Yemen. Ann Saudi Medicine 2000; 20: 464-467. https://doi.org/10.5144/0256-4947.2000.464

11. Al-Shamahy HA, IA Rabbad, A Al-Hababy. Hepatitis B virus serum markers among pregnant women in Sana'a, Yemen. Ann Saudi Med 2003-23:87-89.

12. Sallam TA et al. Prevalence of blood-borne viral hepatitis in different community in Yemen. Epidemiol Infect 2003; 131(1):771-775.https://doi.org/10.5812/hepatmon.6140

13. Scott DA, et al. A sero epidemiological survey of viral hepatitis in Yemen Arab Republic. Transactions of the Royal Society of Tropical Medicine and Hygiene 1990; 84(2):288 291.https://doi.org/10.1016/j.trstmh.2010.08.007

14. Murad EA, Babiker SM, Gasim GI, Rayis DI and Adam I. Epidemiology of hepatitis B and hepatitis C virus infections in pregnant women in Sana'a, Yemen. BMC Pregnancy and Childbirth 2013; 13:113-127. https://doi.org/10.1186/1471-2393-13-127

15. Alodini AQ. Prevalence of Hepatitis B Virus (HBV) and Hepatitis C Virus (HCV) Infections among Blood Donors at Al-Thawra Hospital Sana'a City-Yemen. Yemeni J Med Sci 2012; 6:15-20.https://doi.org/10.3343/alm.2019.39.1.81

16. Al-Waleedi AA, Khader YS. Prevalence of hepatitis B and C infections and associated factors among blood donors in Aden city, Yemen. Eastern Med Health J 2012; 18(6): 1-7. https://doi.org/10.26719/2012.18.6.624

17. Al-Shamahy HA, Samira H Hanash, Iqbal A Rabbad, Nameem M Al-Madhaji, Hepatitis B Vaccine Coverage and the Immune Response in children under 10 years old in Sana'a Yemen. SQU Med J 2011; 11(1): 77-82.

18. Gacche RN, Al Mohani SK. Epidemiology of hepatitis B and C infections in Ibb city Yemen. Hept Mon 2012; 12(7):460462

19. Schillie S, Murphy TV, Sawyer M, Ly K, Hughes E, Jiles R, de Perio MA, Reilly M, Byrd K, Ward JW. CDC Guidance for Evaluating Health-Care Personnel for Hepatitis B virus protection and for administering postexposure management. MMWR. Recommendations and reports: Morbidity and mortality weekly report. Recommendations Reports/ Centers Dis Cont 2013; 62(RR-10): 1-19.PMID: 24352112

20. CSO. Statistical Year-Book supply 1. 2013, Central Statistical Organization (CSO), Ministry of Planning and Development, ROY.

21. MOPH (Ministry of Health and Population). Annual Report of the MOPH, 2012; MOPH, ROY

22. Ott JJ, Stevens GA, Groeger J, Wiersma ST. Global epidemiology of hepatitis B virus infection: new estimates of age-specific $\mathrm{HBs} \mathrm{Ag}$ seroprevalence and endemicity. Vaccine 2012; (12):2212-9. https://doi.org/10.1016/j.vaccine.2011.12.116

23. Yuen MF, Hou JL, Chutaputti A. Hepatocellular carcinoma in the Asia pacific region. J Gastroenterol Hepatol 2009; 24(3):346-53.https://doi.org/10.5009/gnl15257

24. Abdo Ayman A, Sanai Faisal M, Al-Faleh Faleh Z. Epidemiology of viral hepatitis in Saudi Arabia: Are we off the hook? Saudi J Gasteriol 2012; 18(6): 349-357. https://doi.org/10.4103/1319-3767.103425

25. Zanetti AR, Van Damme P, Shouval D. The global impact of vaccination against hepatitis B: a historical overview. Vaccine 2008; 26(49):6266-73. https://doi.org/10.1016/j.vaccine.2008.09.056

26. Alter MJ. Epidemiology of viral hepatitis and HIV coinfection. J Hepatol 2006; 44:S6--9. https://doi.org/10.1016/j.jhep.2005.11.004 